\title{
L'Estat de Valor Afegit: un informe d'interès per a les empreses familiars
}

\author{
José Luis Gallizo Larraz \\ Director de la Càtedra d'Empresa Familiar de la Universitat de Lleida \\ * Correu de contacte: gallizo@aegern.udl.cat
}

Rebut 9 d'octubre 2020; Acceptat 9 de novembre 2020

\begin{abstract}
Resum
Aquest article té per objecte facilitar el coneixement, l'elaboració i interpretació de l'Estat de Valor Afegit (EVA) en el context de la informació financera de les empreses familiars. Comença delimitant la magnitud objecte d'estudi: el valor afegit, després explica com es genera a partir de l'activitat productiva i finalment expressa la seva distribució entre els agents econòmics que contribueixen a la seva formació. Aquest informe no està regulat per la normativa comptable, però, certes companyies mostren la seva preferència per incloure-ho en l'informe de gestió, primer, pel que fa a generadora de valor econòmic i segon, pel que fa a distribuïdora de rendes. Precisament el seu caràcter social fa que aquesta informació sigui d'interès per a una àmplia gamma d'usuaris. Una anàlisi de la distribució del VA a les empreses familiars permet observar si la direcció, mitjançant les seves decisions, preserva o no la seva riquesa emocional generant de vegades tensions entre els agents econòmics que participen d'ell. Aquest coneixement és important per als grups d'interès de l'empresa, així com per a futurs inversors. Finalment, el text presenta els avantatges i inconvenients de la seva divulgació i aporta EVA obtinguts dels informes d'algunes companyies.
\end{abstract}

Classificació JEL: G32, G35, M10.

Paraules Clau: Estat de Valor Afegit, Empresa familiar, Riquesa socioemcional

\section{Concepte de Valor Afegit}

És l'augment en el valor de mercat d'un producte o servei obtingut per una alteració en la forma, localització o disponibilitat. Es mesura per la diferència entre el valor de la producció de béns i serveis i el valor de compra de les adquisicions exteriors (Figura 1).

Pot expressar-se amb la següent igualtat:

Valor Afegit = Valor despeses de l'alteració - Valor abans de l'alteració 
Figura 1. Generació de el valor afegit

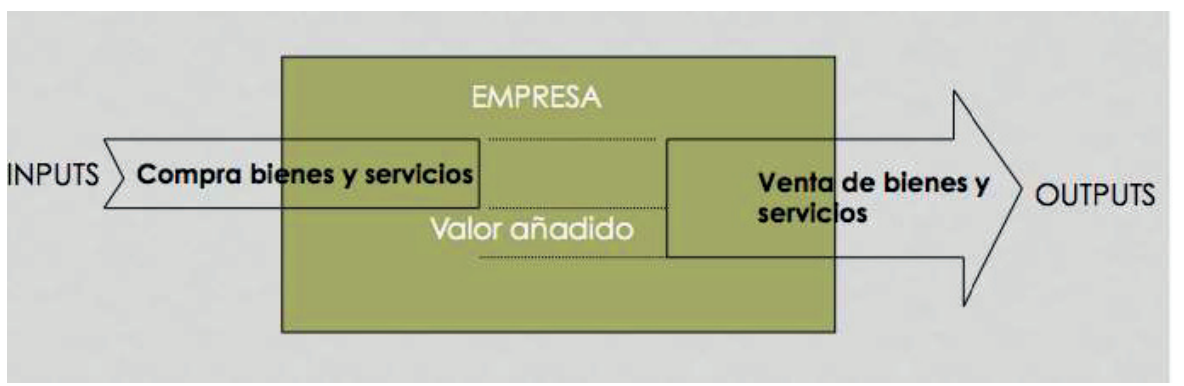

\section{L'Estat de Valor Afegit (EVA). Definició i estructura}

L'Estat de valor afegit (EVA) és un estat econòmic-financer, de circulació real, que mostra el valor econòmic generat per una empresa i desprès descriu com es distribueix entre aquells que han contribuiit a la seva creació.

Per a la seva elaboració serà necessari disposar de dos documents de la comptabilitat tradicional com són:

1) Estat de Resultats

2) Proposta de Distribució Beneficis

\section{I) Estructura l'Estat de Resultats i de la Distribució de Beneficis:}

$P-C-S-I-A-T=U=D+R$

Sent:

$P=$ Valor de la producció.

$C=$ Compres $i$ altres adquisicions exteriors

$S=$ Sous $i$ salaris $i$ altres despeses de personal

$I=$ Interessos de capital aliè

$A=$ Depreciació d'immobilitzat

$T=$ Impost sobre el utilitat $i$ altres tributs

$U=$ Beneficis de l'exercici

$D=$ Dividends

$R=$ Reserves o beneficis retingudes per l'empresa

Modificant l'equació, es pot mostrar la determinació de el valor afegit i la seva posterior distribució entre els agents que han contribuït a la seva formació

\section{II) Estructura de l'estat de valor afegit}

El valor afegit brut i la seva distribució pot representar-se com segueix:

$V A=P-C=S+I+A+T+D+R$

On es mostra l'adopció d'una suposició de la teoria econòmica fonamental, expressiva d'una igualtat entre valor afegit i la renda dels diferents grups que participen en l'activitat productiva de l'empresa. De les anteriors expressions es pot deduir que la 
utilitat és un component del VA, ja que en definitiva suposa una participació més en aquest valor, precisament la dels propietaris de l'empresa. De manera que, a la qüestió de què partides hauríem de sumar a la utilitat per obtenir el valor afegit? la resposta és evident, aquelles comptes de despeses que representen remuneració de factors, és a dir,

$V A=U+S+I+A+T$

És a dir, la suma de benefici que correspon als accionistes, més els sous i salaris dels treballadors, més els interessos dels préstecs, més la depreciació de l'actiu fix i més els tributs [3]. Es tracta de la suma de les compensacions econòmiques que l'empresa distribueix entre els seus partícips i l'assignació de despesa per depreciació per a renovació d'actius.

\section{Presentació de l'Estat de Valor Afegit (EVA)}

L'EVA és un estat comptable que es compon de dues parts:

\section{1) Generació i}

2) Distribució.

\subsection{Generació de Valor Afegit}

Expressa el valor generat a partir de la valor de la producció (venuda, emmagatzemada i immobilitzada), menys els consums necessaris per obtenir-la $i$ altres despeses i ingressos d'operacions.

El valor afegit generat ha de coincidir amb el valor afegit distribuït. No obstant això, en aquells casos en què l'empresa hagi obtingut rendes procedents d'altres entitats (dividends, interessos o resultats excepcionals), el valor afegit obtingut per la suma de remuneracions, no seria coincident amb el valor afegit aconseguit per la pròpia activitat empresarial (producció - adquisicions exteriors). Per solucionar aquesta manca de coincidència, se sol adoptar un format en dos nivells que permet quadrar l'estat comptable.

\begin{tabular}{|c|}
\hline Valor afegit de l'empresa \\
\hline $\begin{array}{c}\text { + Ingressos financers } \\
+ \text { Resultats excepcionals }\end{array}$ \\
\hline Valor afegit total \\
\hline
\end{tabular}

En un primer nivell, es mostra el valor afegit referit exclusivament a les activitats realitzades per l'empresa, per a després afegir els resultats procedents d'altres entitats, $\mathrm{i}$ arribar al valor afegit total, importat coincident amb la suma de remuneracions dels participes en les rendes de l'empresa.

\subsection{Distribució de valor afegit}

A la segona part de l'EVA s'informa del import assignat a cada un dels 5 grups socials que han contribuït a la seva formació.

- 1r. Els treballadors, obtenen remuneracions en forma de sous i salaris, seguretat social, plans de pensions i altres tipus de prestacions socials. 
- 2n. Els propietaris de l'empresa familiar, són remunerats a partir dels beneficis obtinguts pel negoci en forma de dividends actius (dividends a compte i complementaris)

- 3r. Els aportants de capital aliè, és a dir, entitats financeres o bancs, que són remunerats mitjançant els interessos dels préstecs (despeses financeres).

- 4t. L'Estat, a què l'empresa fa partícip de la seva riquesa generada mitjançant el pagament d'impostos, bàsicament, amb l'impost sobre beneficis i altres tributs.

- 5è. La pròpia empresa, retenint en el seu balanç una part d'aquest valor generat per dues finalitats:

○ per a manteniment d'actius, mitjançant les dotacions d'amortitzacions

○ per la seva expansió, amb les dotacions a reserves.

L'anàlisi temporal de la distribució de el valor afegit és molt útil per estimar el pagament de les rendes generades i anticipar les tensions que les mateixes poden implicar. Conflictes entre sindicats i empresaris, accionistes i gerència, poden analitzar mitjançant les sèries històriques de repartiment de VA i amb elles predir comportaments futurs (Gallizo et al, 2002).

Per a l'estudi dels estils de direcció de les empreses familiars enfront de les no familiars, l'EVA és un estat comptable molt apropiat, especialment, si es presenta com un document de responsabilitat social corporativa (RSC). També, si les dades de l'EVA estan disponibles a un conjunt d'empreses, es pot identificar quina part del VA s'ha dedicat a sous, interessos de préstecs, depreciació i impostos i analitzant la porció de cada un d'aquests components en el VA es poden explorar les eleccions de repartiment fetes per les empreses familiars enfront de les empreses no familiars (Gallizo et al, 2017).

Pel que fa a la manera de presentar l'estat comptable, no hi ha un esquema normalitzat. Algunes empreses opten senzillament per un estat de distribució de rendes per evitar el desquadrament entre el valor generat $\mathrm{i}$ el distribuït, però la majoria opten per un model complet. En el següent apartat fem una proposta de model general, on la inclusió d'una columna de percentatge de valor afegit és útil per facilitar l'anàlisi de les respectives parts de renda lliurades a cada un dels grups-particeps.

\section{Estructura de l'Estat de Valor Afegit}

L'EVA es pot concebre com una versió modificada de l'estat de resultats i encara que es contempla la seva existència en l'Informe Anual de nombroses empreses, encara no es disposa d'un model normalitzat internacionalment.

La Norma Internacional d'Informació Financera número 1 de l'international Accounting Standard Board (IASB) reconeix que moltes entitats presenten, addicionalment als seus estats financers altres informes i estats com ara els relatius a l'estat de valor afegit o a la informació mediambiental, particularment en sectors industrials on els treballadors es consideren un important grup d'usuaris o bé els factors del medi ambient resulten significatius, respectivament. Aquests informes i estats presentats a part dels estats financers, quedaran fora de l'abast de les NIIF. 
Davant la falta d'una referència d'estat normalitzat, proposem l'esquema de la Taula 1 basat en l'estructura de l'Estat de Resultats de la International Accounting Standard $n^{\circ} 1$, en concret, extraiem el primer tram de l'esmentat estat comptable on s'expressa l'acumulació bruta de valor.

Taula 1. Model d'Estat de Valor Afegit

\begin{tabular}{|c|c|c|c|}
\hline & $20 \times 2$ & $20 \mathrm{X} 1$ & $\begin{array}{c}(\%) \\
20 X 2\end{array}$ \\
\hline $\begin{array}{l}\text { GENERACIÓ } \\
\text { Import net xifra de negocis } \\
\text { + Variació d'inventari de productes acabats i en } \\
\text { procés de fabricació } \\
\text { + Treballs realitzats per l'empresa per al seu } \\
\text { actiu } \\
\text { (-) Consum de materials } \\
\text { + Ingressos d'explotació } \\
\text { + Subvencions d'explotació } \\
\text { (-) Despeses d'explotació }\end{array}$ & & & \\
\hline Valor Afegit Brut & & & \\
\hline $\begin{array}{l}\text { + Ingressos financers } \\
+ \text { Ingressos i despeses excepcionals }\end{array}$ & & & \\
\hline Valor afegit total (rendes generades) & & & \\
\hline $\begin{array}{l}\text { DISTRIBUCIÓ } \\
\text { 1. A el factor treball (empleats) Sous i salaris } \\
\text { Seguretat Social a càrrec d'empresa Altres } \\
\text { prestacions socials } \\
\text { 2. Al capital propi (accionistes) dividends } \\
\text { actius } \\
\text { 3. Al capital aliè (bancs) Interessos de préstecs } \\
\text { 4. A l'Estat. Impost sobre utilitats altres tributs } \\
\text { 5. A la mateixa empresa. Amortitzacions } \\
\text { d'immobilitzat Dotacions a reserves (beneficis } \\
\text { retinguts) }\end{array}$ & & & \\
\hline Valor afegit total (rendes generades) & & & \\
\hline
\end{tabular}

L'EVA es presenta de maneres diferents segons sigui la tradició de país a què pertany l'empresa. Així a Alemanya, l'amortització no forma part de la distribució del VA, sinó que es resta en el càlcul de la generació de valor, a la fi, les empreses alemanyes distribueixen un VA Net.

Aquesta pràctica té la seva raó de ser en la importància que donen els sindicats alemanys a la informació comptable en les negociacions salarials. Així, l'empresa per intentar donar la millor imatge davant els representants dels treballadors transmeten el repartiment d'un VA net en el qual es vegi que el percentatge destinat a la feina és més gran que si el càlcul s'hagués fet sobre un VA brut (veure quadre 5). 


\section{Aportació a la Renda Nacional d'una empresa familiar com "El Corte Inglés",} Informe 2016.

El Corte Inglés és una SA de caràcter familiar pel fet que el control de l'empresa està en mans de membres de la família. Amb una xifra de vendes al voltant de 15.000 milions d'euros, ocupa a 88.000 empleats.

La seva importància és de tal calibre que tradicionalment informa en la seva memòria anual, en milions d'euros, l'aportació que realitza a l'economia nacional.

Taula 2. Estat de Repartiment de Valor Afegit de "El Corte Inglés" 2016

\begin{tabular}{|l|r|r|}
\hline \multicolumn{1}{|c|}{ Distribució del Valor Afegit } & \multicolumn{1}{c|}{$€$} & \multicolumn{1}{c|}{$\%$} \\
\hline Al Treball & $2.093,53$ & $55,48 \%$ \\
\hline A l'Estat, Comunitats autònomes i corporacions locals & $1.447,96$ & $38,37 \%$ \\
\hline Als accionistes (repartiment de dividends) & 40,5 & $1,07 \%$ \\
\hline A la mateixa empresa & 191,63 & $5,08 \%$ \\
\hline Total distribució de rendes & $\mathbf{3 . 7 7 3 , 6 2}$ & $100 \%$ \\
\hline
\end{tabular}

El Corte Inglés informa de l'aportació a la renda nacional presentant-la com un veritable estat de repartiment de valor afegit entre els diferents agents que han contribuit a la seva formació.

En el quadre 4 hem preparat en forma d'estat comptable la informació subministrada per la companyia. Es pot observar a la Figura 2 extreta de la memòria de la companyia una representació mitjançant un gràfic de sectors del repartiment del valor afegit de "El Corte Inglés".

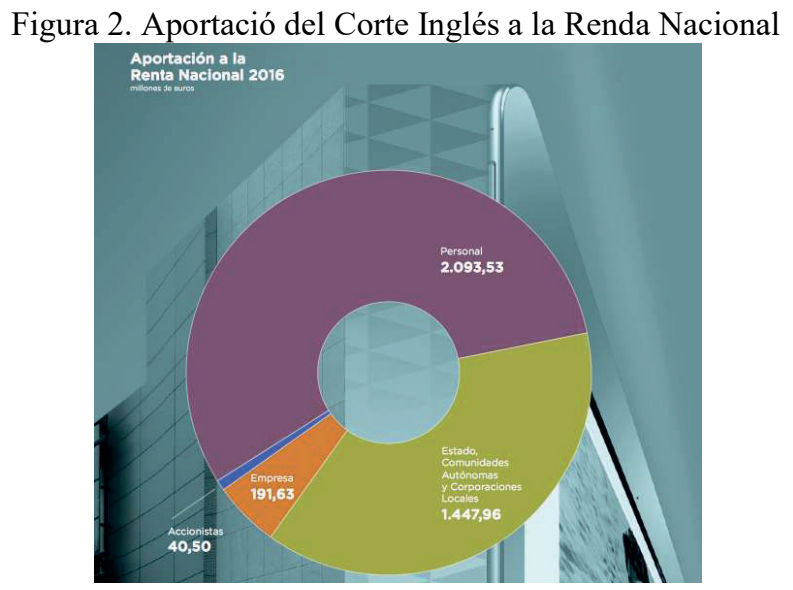

\section{Versió GRI del Valor Generat}

El GRI (Global Reporting Initiative) és una organització multisectorial global sense ànim de lucre, té per objecte fer que la presentació d'Informes de Sostenibilitat sigui més efectiva i comparable a tot el món. El primer indicador econòmic proposat per als informes de sostenibilitat és el G4 EC1 Valor Econòmic Directe Generat i Distribuït. 
La versió del GRI del "valor econòmic" és diferent a la tradicional de Valor Afegit. Segons l'apartat EC1 de GRI, l'import que es distribueix entre els diversos agents és la xifra de negocis més els ingressos financers i els cobraments procedents de vendes d'actius. No és per tant, una diferència, ni pròpiament un valor afegit el que s'assigna als factors de la producció, sinó una quantitat més gran, representada pels ingressos totals de el període (Gallizo, 2007).

El protocol d'indicadors EC del GRI en el seu apartat EC1 es refereix al Valor econòmic generat i distribuït (VEG \& D) com aquell que inclou ingressos, costos operatius, remuneració d'empleats $\mathrm{i}$ altres aportacions a la comunitat, a més de beneficis retinguts $\mathrm{i}$ pagaments als aportants de capital i a l'Estat. Diverses entitats a Espanya segueixen la línia d'informar sobre aquest valor econòmic en les seves memòries o informes anuals.

\section{Anàlisi de la distribució de VA}

Per a una anàlisi de repartiment de rendes, l'estat de valor afegit és la millor manera de posar en un únic document i en la mateixa perspectiva els interessos dels diferents agents econòmics involucrats en l'activitat de l'empresa.

La competència entre els diferents partícips per apropiar-se de la major porció de VA és una cosa contrastable. En (Gallizo et al, 2002), s'estudia empíricament les tensions que genera en èpoques de crisi econòmica la pretensió d'un determinat grup social d'ampliar o mantenir la quota en el repartiment de rendes.

En empreses familiars, a més dels mecanismes necessaris en tota organització, s'han d'establir mecanismes complementaris que ordenin les relacions familiars i les econòmiques i evitin polítiques expropiatòries de el valor creat per part d'alguns participants familiars. Entre aquests instruments podem citar la reunió, l'assemblea o el consell de família i el protocol familiar, que tracten d'assegurar que només els aspectes positius del caràcter familiar influeixin en l'empresa $i$ evitar que els inconvenients d'aquesta naturalesa facin perillar la supervivència a llarg termini de la mateixa (Cabrera i Santana, 2002)

\section{A) Remuneració al Treball}

La ràtio de retribució als empleats ve donat per:

$$
\text { Ratio retribució treballadors }=\frac{\text { Despeses de personal }}{V A \text { Total }}
$$

Expressa l'import que l'empresa ha destinat en concepte de despeses de personal per aconseguir a obtenir $1 \mathrm{u}$.m. de VA. Una millora de la ràtio suposa un increment en la productivitat laboral. Des del punt de vista dels treballadors, la ràtio mostra la seva participació amb relació als altres beneficiaris en la distribució, podent argumentar com una reivindicació laboral, o com un incentiu a l'augment de productivitat en el treball, el manteniment d'un cert paral lelisme entre taxa de creixement real en el volum de rendes generades per unitat salarial i l'import de despeses de personal en termes reals.

\section{B) Remuneració al Capital Aliè}

En aquest apartat considerem la retribució al capital financer extern utilitzat per l'empresa, despeses meritades durant el període en concepte d'interessos. Els comptes a considerar són les compreses en Despeses financeres. 
En termes econòmics, la retribució al capital aliè és entesa com un factor de producció i com a tal s'ha de considerar en l'anàlisi de la distribució de rendes, acceptant el caràcter canviant de les taxes d'interès, en funció de les circumstàncies particulars del mercat financer.

La ràtio de rendes destinades als subministradors de capital aliè ve donat per:

$$
\text { Ratio retribució capital alié }=\frac{\text { Despeses financeres }}{V A \text { Total }}
$$

Informa de l'import d'interessos de deute que l'empresa ha meritat com a remuneració al capital aliè per obtenir 1 u.m. de VA total. El resultat de la ràtio, pot així mateix ser usat per les institucions financeres en anàlisi temporal, com un indicador més, en la predicció de la tornada esperada per interessos, i en conseqüència deduir el risc assimilat als seus crèdits.

\section{C) Aportació a l'Estat}

Tot $\mathrm{i}$ que en alguns casos no es compti amb que l'Estat és factor contribuent en la producció de les empreses, és innegable que juga un paper d'agent econòmic de gran importància, col-laborant de forma indirecta amb l'activitat productiva de el sector empresarial. En efecte, «l'Estat dóna suport amb inversions d'estructura, a part de prestar altres serveis d'infraestructura a la creació de valor, l'Estat, administrador d'impostos i altres ingressos, efectua les inversions necessàries per al desenvolupament de sistema socioeconòmic»»

La ràtio corresponent a la participació de l'Estat ve donat per:

$$
\text { Participació de l'Estat }=\frac{\text { Impost sobre beneficis }+ \text { Altres tributs }}{\text { VA Total }}
$$

Informa de l'aportació de l'empresa a l'Estat sobre el VA. Es fa a través dels impostos que ha de pagar l'empresa periòdicament, tenint present que a efectes de determinar el muntant d'aquesta contribució, només podrem computar l'impost sobre el utilitat i altres tributs lligats directament a l'explotació; és a dir, aquells impostos en què l'empresa suporta el gravamen, veient disminuït el seu patrimoni en l'import del tribut.

Per tant, hauran de quedar fora d'aquest còmput les retencions de rendes de capital que l'empresa practiqui sobre interessos de préstecs, o sobre dividends d'accions, també les retencions en nòmina dels treballadors per impost de la renda, i l'import corresponent d'Hisenda pública creditor per IVA, en aquests casos, l'empresa és un simple recaptador amb la consideració de subjecte passiu jurídic, però no econòmic.

\section{D) Retribució al Capital Propi}

La ràtio de participació del capital propi Informa de la part de valor afegit destinat a pagar dividends als socis i ve donat per:

$$
\text { Participació capital propi }=\frac{\text { Dividends actius }}{\text { VA Total }}
$$


La decisió de repartir o retenir utilitats correspon a la Junta General de la societat, que la prendrà atenent als seus interessos $\mathrm{i}$ estratègies. Per exemple, una empresa familiar on predomini el finançament intern, destinarà la major part de les seves utilitats a autofinançament $i$ els socis estaran d'acord a l'identificar-se amb les decisions preses per la família.

\section{E) Participació de la pròpia empresa}

La ràtio Informa de la generació pròpia de recursos; tant pel que fa a dotar les corresponents depreciacions de el període, com a constituir les oportunes reserves que permetin enfortir el potencial econòmic empresarial.

$$
\text { Participació pròpia empresa }=\frac{\text { Dotacions depreciació actiu fix } i \text { reserves }}{\text { VATotal }}
$$

Per tant, dos conceptes hem de distingir com a integrants d'aquesta aplicació: un les depreciacions, i un altre l'excedent final destinat a reserves, aquest és l'import que queda un cop distribuiits els imports corresponents a la resta de partícips. La suma de dotacions per depreciació de l'actiu fix i de reserves, representen els fons autogenerats internament.

\section{Anàlisi de l'empresa mitjançant el valor afegit.}

Les ràtios basats en el VA s'han plantejat com les mesures de productivitat més sensibles, amb alt valor predictiu i per tant rellevants per planificar el futur de l'empresa. Les ràtios de VA també mostren el nivell d'eficiència en dos diferents factors:

- Treball (productivitat de la feina, calculada per "VA / núm empleats", "VA / hores treballades").

Considerem una empresa més eficient que una altra si produeix més valor afegit per treballador controlant la intensitat del capital i la mida de l'empresa (Galve i Sales, 1996).

- Capital financer (productivitat del capital, calculada per "VA / Capital financer invertit)

\subsection{Mesura d'Integració Vertical}

La integració vertical suposa la realització de més d'una activitat dins de la cadena de valor afegit. Una empresa integrada verticalment podria realitzar totes les etapes d'obtenció i transformació de la matèria primera per aconseguir un producte elaborat, podent-se ocupar ella mateixa de les activitats de proveïment, producció i distribució. Si la companyia s'integra verticalment s'està diversificant la seva activitat.

La ràtio de valor afegit / vendes ha estat suggerit com una mesura d'integració vertical.

$$
\text { Ràtio de valor afegit }(R 1)=\frac{\text { Valor } A \text { fegit }}{\text { Ingressos per vendes }}
$$

El Ràtio de valor afegit (R1), pot ser interpretat com un índex de vulnerabilitat a actuacions que afecten el subministrament de materials i serveis. Un elevat valor de R1 
indicarà independència econòmica de l'empresa davant els canvis estructurals del mercat $\mathrm{i}$ als seus impactes en la productivitat operacional. Una empresa totalment integrada tindria una relació igual a un. Morley (1981) proporciona la següent explicació:

Si una empresa té plantacions forestals, tala la seva pròpia fusta, la processa $i$ finalment fabrica productes de fusta, llavors la seva relació de valor afegit amb les vendes serà alta, ja que els costos de compra seran bastant baixos. No obstant això, si una altra empresa es limita a la fabricació de productes de fusta tindrà tots els seus costos d'adquisició i processat de la fusta com comprats, el que donarà a aquesta una proporció més baixa de valor afegit respecte a les vendes.

\subsubsection{Productivitat de personal}

Quan el valor afegit es combina en forma de ràtio amb una xifra que mesuri algun atribut dels costos laborals, s'obtindran indicadors de productivitat.

Així, la productivitat del personal, es calcula com el valor afegit per nombre d'empleats i valor afegit per nombre d'hores treballades. En Economia aquesta ràtio es determina per a cada sector industrial i s'anomena Productivitat Aparent. Per a l'anàlisi d'empreses s'usa amb més freqüència la relació de el valor afegit amb els sous $i$ altres despeses socials meritades (R2)

$$
\text { Ràtio de productivitat de personal }(R 2)=\frac{\text { Valor afegit }}{\text { Despeses de personal }}
$$

Qualsevol analista esperarà que R2 sigui més gran que la unitat, una empresa amb R2 < 1 no podria sostenir indefinidament, significaria que als treballadors se'ls està pagant més de la valor total de la seva output i abans de deduir cap altra retribució.

Mitjançant l'evolució de la ràtio R2, la gerència pot expressar els canvis socials experimentats dins de l'empresa. Així, els sous i salaris i la seva importància depenen de diferents estratègies, per exemple, la mesura en què es derivi part de la producció a l'exterior, l'existència de sistemes de participació dels empleats en els resultats de l'empresa i la inclusió, o no de disposicions de prestacions socials.

La ràtio de productivitat dóna resposta a la següent qüestió: Per cada 1 euro consumit en despeses de personal, quants euros obté l'empresa de valor afegit?

El resultat de la ràtio, comparat amb les empreses de el sector ens indicarà la productivitat de personal relativa aconseguida per la signatura, també seria interessant analitzar l'evolució temporal.

\section{Avantatges i insuficiències de l'Estat de Valor Afegit (EVA)}

\subsection{Avantatges}

1a. Neutralitat. L'EVA transmet la distribució d'un excedent econòmic en què intervenen diferents estaments i grups socials amb expectatives sobre el mateix, de vegades contraposades. 
L'EVA és un document de suport, tant per interessos d'un determinat grup social, com per als d'altres, que en un moment poguessin entrar en competència. Aquesta falta d'inclinació cap a interessos particulars, el fa ser un document base en les negociacions d'un conveni col·lectiu.

2a. L'EVA ajuda a crear un clima organitzacional adequat entre els treballadors al realçar la seva importància en els resultats finals de l'empresa. Està comprovat que la presentació de l'EVA incrementa l'actitud positiva i favorable dels empleats cap a la companyia per mostrar-los que, normalment, són ells els principals partícips en la renda generada, motivant-los a realitzar un millor treball, amb major cooperació i identificantse amb la pròpia empresa (Belkaoui, 2010).

$3^{\mathrm{a}}$. De les dades de l'EVA s'extreuen interessants mesures de productivitat laboral, podent-se establir incentius a la feina, segons siguin els increments de productivitat obtinguts sobre els canvis en l'import de valor afegit.

4. La informació del VA pot servir com una bona mesura de la mida i de la importància relativa de les empreses. Així ho ha entès la Central de Balanços del Banc d'Espanya, a l'utilitzar com a criteri de classificació per grandàries de les empreses objecte de la seva anàlisi a més de la xifra de negocis i de el nombre de treballadors, la xifra de valor afegit generat en el període.

5è. L'EVA representa la contribució de l'empresa al PIB de la nació, i per tant té l'interès de ser la xifra sobre la qual pivota el lligam entre la comptabilitat empresarial i la macroeconòmica. Tal és així que certs bancs espanyols presenten en els seus informes anuals estats de repartiment de VA, expressant a través d'aquesta mesura l'aportació de l'entitat a la formació de la producció global de país.

\subsection{Insuficiències}

1a. El problema de la manca de normalització de l'EVA, motivat en part, per la no inclusió del VA en els Comptes Anuals de la Quarta Directiva, i aquesta al seu torn, per no haver existit en l'IASB cap iniciativa al respecte és un inconvenient de aquest estat comptable.

2a. La utilització de l'EVA pot confondre als seus usuaris en aquells casos en què el VA s'incrementi, mentre els guanys disminueixin. En aquestes situacions, els accionistes no trobaran una explicació en l'EVA s'han de fixar a l'Estat de resultats i deixar l'EVA com un document dirigit a un ampli grup d'agents econòmics.

$3^{\text {a }}$. L'establiment de l'EVA pot influir en determinats directius d'empreses per aconseguir l'objectiu de maximització del VA. Això que en principi pot plantejar-se com una interessant fita a assolir, pot conduir a prendre decisions errònies quan això provoqui una disminució de la rendibilitat financera, fins i tot en situacions extremes aquest objectiu podria arribar a posar en perill la continuïtat de l'empresa.

\section{Reflexió final}

La presentació d'informes sobre valor afegit, encara que no sempre és obligatòria, s'està fent cada vegada més popular a Europa, Sud-àfrica, Austràlia, algun país d'Amèrica Llatina i Singapur. Aquesta pràctica informativa té una estreta vinculació amb la 
Responsabilitat Social Corporativa (RSC) i s'identifica amb la comptabilitat socioeconòmica (Perera i Zicari, 2012).

Recentment, a Europa, després de la posada en vigor de la directiva d'informació no financera i de l'Informe Integrat (Integrated Reporting) s'està generalitzant la informació social i mediambiental de les empreses incorporant en molts casos l'EVA com un dels informes imprescindibles en el conjunt d'aquesta informació.

Donada la creixent difusió de l'EVA per a fins d'informació socioeconòmica, hi ha organismes i autors que avui clamen per avançar en la seva normalització. Disposar d'un format d'EVA reconegut per un organisme solvent facilitaria la comparabilitat entre les empreses i evitaria la discrecionalitat en el seu ús. Referent a això, estan apareixent nous intents de normalització, és el cas de la Comissió de Principis i Normes de Comptabilitat de l'Associació Espanyola de Comptabilitat i Administració d'Empreses (AECA) amb una proposta relativa a la valor afegit com a mesura alternativa de rendiment empresarial (Gonzalo i Pérez, 2017).

El clar missatge transmès per l'informe de valor afegit és que la riquesa creada en la producció és el resultat de l'esforç combinat d'un equip de membres cooperadors. La gerència de l'empresa familiar en l'arbitratge del conflicte del repartiment de la valor pot barrejar els objectius familiars i empresarials, el que aguditzarà els seus problemes d'autocontrol o conflictes d'interès interns. Aquesta dualitat d'objectius en la gerència pot provocar comportaments altruistes i desequilibris en el repartiment de valor que impliquin un transvasament de valor d'uns participants cap a altres. L'estat de valor afegit jugarà un important paper informatiu a les empreses familiars que vulguin demostrar amb xifres l'evolució de les participacions percebudes pels diferents agents involucrats.

\section{Referències}

Belkaoui, A. (2010). "Wealth and Value Added: Reporting, Analysis, Prediction, and Taxation”. ISBN: 1450511600, https://www.researchgate.net.

Cabrera, K. i Santana, D. (2002): "El gobierno de la empresa familiar". Boletín de Estudios Económicos, 57,(177),467-481.

Galve, C. i Salas, V. (1996). "Ownership Structure and Firm Performance: Some Empirical Evidence from Spain”. Managerial and Decision Economics, 17, 575-586.

Gallizo, José L. (2007). "Valor económico y su distribución en los informes de sostenibilidad". Revista AECA, 78, 34-37.

Gallizo, J.L.; Gargallo, P. i Salvador, M. (2002). "Sharing Wealth: Evidence from Financial Ràtios in Spain". Journal of International Financial Management and Accounting, 13:3, 214-234.

Gallizo, J.L.; Mar-Molinero, C.; Moreno, J. i Salvador, M. (2017). "Family business and value-added distribution: a socioemotional wealth approach", Academia Revista Latinoamericana de Administración, 30 (1) 2-22.

Gonzalo, J.A. i Perez, J. (2017). "Una propuesta de normalización relativa al valor añadido como medida alternativa de rendimiento empresarial". Revista de la Asociación de Contabilidad y Administración de Empresas, 119, 35-39. 
Morley, M.F. (1981). "Value Added Reporting". In Developments in Financial Reporting”, edited by Thomas A. Llegeix, 251-269. London: Philip Allan.

Perera Aldama, L. i Zicari, A., (2012). "Value-added reporting as a tool for sustainability: a Latin American experience", Corporate Governance: The international journal of business in society, 12(4), $485-498$. 